\title{
Body mass index, height and risk of adenocarcinoma of the oesophagus and gastric cardia: a prospective cohort study
}

\author{
Audrey H H Merry, Leo J Schouten, R Alexandra Goldbohm, Piet A van den Brandt
}

Gut 2007;56:1503-1511. doi: 10.1136/gut.2006.116665

See end of article for authors' affiliations

Correspondence to: Audrey H H Merry,

Maastricht University, PO

Box 616, 6200 MD,

Maastricht, Netherlands;

audrey.merry@epid.

unimaas.nl

Revised 23 February 2007

Accepted 27 February 2007

Published Online First

1 March 2007

\begin{abstract}
Background: In the last decades, the incidence of oesophageal and gastric cardia adenocarcinoma has increased rapidly in the Western world. We investigated the association between body mass index (BMI), height and risk of oesophageal and gastric cardia adenocarcinoma.

Methods: The Netherlands Cohort Study was initiated in 1986. All participants ( $n=120852)$, aged 5569 years, completed a self administered questionnaire. Cases were identified through annual record linkage with the Netherlands Cancer Registry. After 13.3 years of follow-up, excluding the first follow-up year, complete data from 4552 subcohort members, 133 oesophageal and 163 gastric cardia adenocarcinomas were available for case-cohort analyses. Incidence rate ratios (RRs) and corresponding $95 \%$ confidence intervals were estimated using Cox proportional hazard models.

Results: The RRs (95\% Cl) of oesophageal adenocarcinoma were 1.40 (0.95 to 2.04) and 3.96 (2.27 to 6.88) for overweight (BMI $25.0-29.9 \mathrm{~kg} / \mathrm{m}^{2}$ ) and obese subjects $\left(B M I \geqslant 30.0 \mathrm{~kg} / \mathrm{m}^{2}\right)$, respectively, compared to subjects with normal weight (BMl $20.0-24.9 \mathrm{~kg} / \mathrm{m}^{2}$ ). For gastric cardia adenocarcinoma, these RRs were 1.32 (0.94 to 1.85 ) and 2.73 (1.56 to 4.79 ). Also change in BMI during adulthood was positively associated with the risk of oesophageal and gastric cardia adenocarcinoma ( $p$ trend 0.001 and 0.02 , respectively), while no association was found with $\mathrm{BMI}$ in early adulthood ( $\mathrm{p}$ trend 0.17 and 0.17 , respectively). None of the tumour types investigated was significantly associated with height.

Conclusions: These results confirm higher risks of oesophageal and gastric cardia adenocarcinoma with increasing BMI. This implies that the increasing prevalence of obesity may be one of the explanations for the rising incidence of oesophageal and gastric cardia adenocarcinoma in the Western world.
\end{abstract}

। $\mathrm{n}$ the last decades, the incidence of adenocarcinoma of the oesophagus and gastric cardia has increased rapidly in the United States and Western Europe, including the Netherlands. ${ }^{1-4}$ In contrast, the incidence of oesophageal squamous cell carcinoma has been stable, while the incidence of distal gastric adenocarcinoma has declined. ${ }^{135}$ It has been suggested that the increasing prevalence of obesity in the Western world $^{67}$ explains these trends in incidence of adenocarcinoma of the oesophagus and gastric cardia. A recently published meta-analysis showed a positive association between body mass index (BMI) and risk of adenocarcinoma of the oesophagus and possibly of the gastric cardia. ${ }^{8}$ For oesophageal squamous cell carcinoma, however, no association was found with BMI in some studies, ${ }^{5}$ ' while others found an increasing BMI to be associated with decreased risk. ${ }^{10-13}$

Only a few case-control studies studied BMI at age 20 and found that this factor was positively associated with oesophageal and gastric cardia adenocarcinoma. ${ }^{9}{ }^{14}{ }^{15}$ Some studies also investigated the association between height and these tumour types. For oesophageal squamous cell carcinoma and adenocarcinoma the results were inconclusive, while no association was found between height and gastric cardia adenocarcinoma. ${ }^{5}{ }^{14} 16-19$

It has been suggested that central obesity leads to a higher intra-abdominal pressure, which may result in a higher frequency of gastro-oesophageal reflux. ${ }^{20-24}$ Frequent reflux of the gastric acid or bile into the oesophagus may result in a change of the squamous cell epithelium into a metaplastic epithelium in the lower third of the oesophagus, a condition called Barrett's oesophagus. This condition is thought to be a premalignant lesion for the development of oesophageal adenocarcinoma. Several authors, therefore, have suggested that obesity may increase the risk of oesophageal adenocarcinoma through a higher frequency of gastro-oesophageal reflux. ${ }^{51125}$ Whether this mechanism also applies to gastric cardia adenocarcinoma is unknown, although a modest but statistically significant relation with gastro-oesophageal reflux was found in one study. $^{24}$

Most of the studies included in the meta-analysis on BMI and the risk of adenocarcinoma of the oesophagus and gastric cardia were case-control studies. ${ }^{8}$ Such studies are more vulnerable to information and selection bias, especially hospital based case-control studies. Only three prospective studies investigated the association between BMI and the risk of oesophageal and/or gastric cancer. ${ }^{13}{ }^{17} 18$ However, only one of these studies investigated the risk of both oesophageal and gastric cardia adenocarcinoma. ${ }^{13}$ We therefore examined the association between BMI and the risk of oesophageal and gastric cardia adenocarcinoma in the Netherlands Cohort Study on Diet and Cancer. For comparison purposes, we also investigated the association with BMI for oesophageal squamous cell carcinoma and non-cardia gastric adenocarcinoma. Because only a few case-control studies investigated BMI in early adulthood ${ }^{914}{ }^{15}$ or change in weight during adulthood, ${ }^{512}$ the effects of BMI at age 20 years, change in BMI and height were also evaluated for all tumours in this prospective study.

\section{MATERIALS AND METHODS}

\section{The cohort}

In September 1986, the Netherlands Cohort Study on Diet and Cancer was initiated. The cohort included 58279 men and 62573 women who were aged 55-69 years at baseline. Data processing and analysis were based on a case-cohort design:

Abbreviations: BMI, body mass index; LOS, lower oesophageal sphincter; NOS, not otherwise specified; RR, rate ratios 
Table 1 Confounder sets for multivariate analyses with anthropometric variables in the Netherlands Cohort Study on Diet and Cancer, 1986-1999*

\begin{tabular}{|c|c|c|c|c|c|}
\hline \multirow[b]{2}{*}{ Anthropometrics } & \multicolumn{2}{|l|}{ Oesophagus } & \multicolumn{3}{|l|}{ Stomach } \\
\hline & $\begin{array}{l}\text { Squamous cell } \\
\text { carcinoma }\end{array}$ & Adenocarcinoma & $\begin{array}{l}\text { Gastric cardia } \\
\text { adenocarcinoma }\end{array}$ & $\begin{array}{l}\text { Adenocarcinoma distant } \\
\text { stomach }\end{array}$ & $\begin{array}{l}\text { Adenocarcinoma stomach, } \\
\text { NOS }\end{array}$ \\
\hline BMI at baseline & $\begin{array}{l}\text { Age } \\
\text { Sex } \\
\text { Smokingt }\end{array}$ & $\begin{array}{l}\text { Age } \\
\text { Sex }\end{array}$ & $\begin{array}{l}\text { Age } \\
\text { Sex }\end{array}$ & $\begin{array}{l}\text { Age } \\
\text { Sex } \\
\text { Smoking } \\
\text { Education } \ddagger\end{array}$ & $\begin{array}{l}\text { Age } \\
\text { Sex } \\
\text { Smoking } \\
\text { Education } \\
\text { History of gastric ulcers or } \\
\text { bleeding }\end{array}$ \\
\hline $\mathrm{BMl}$ at age 20 years & $\begin{array}{l}\text { Age } \\
\text { Sex } \\
\text { Smoking }\end{array}$ & $\begin{array}{l}\text { Age } \\
\text { Sex }\end{array}$ & $\begin{array}{l}\text { Age } \\
\text { Sex }\end{array}$ & $\begin{array}{l}\text { Age } \\
\text { Sex } \\
\text { Smoking } \\
\text { Education }\end{array}$ & $\begin{array}{l}\text { Age } \\
\text { Sex } \\
\text { Smoking } \\
\text { Education } \\
\text { History of gastric ulcers or } \\
\text { bleeding }\end{array}$ \\
\hline $\begin{array}{l}\text { Change in } B M l \text { since } \\
\text { age } 20 \text { years }\end{array}$ & $\begin{array}{l}\text { Age } \\
\text { Sex } \\
\text { BMl at age } 20 \text { years } \\
\text { Smoking }\end{array}$ & $\begin{array}{l}\text { Age } \\
\text { Sex } \\
\text { BMl at age } 20 \text { years }\end{array}$ & $\begin{array}{l}\text { Age } \\
\text { Sex } \\
\text { BMl at age } 20 \text { years }\end{array}$ & $\begin{array}{l}\text { Age } \\
\text { Sex } \\
\text { BMl at age } 20 \text { years } \\
\text { Smoking } \\
\text { Education }\end{array}$ & $\begin{array}{l}\text { Age } \\
\text { Sex } \\
\text { BMl at age } 20 \text { years } \\
\text { Smoking } \\
\text { Education } \\
\text { History of gastric ulcers or } \\
\text { bleeding }\end{array}$ \\
\hline Height at baseline & $\begin{array}{l}\text { Age } \\
\text { Sex } \\
\text { BMI at baseline } \\
\text { Smoking } \\
\text { Alcohol intake } \\
\text { Fruit consumption }\end{array}$ & $\begin{array}{l}\text { Age } \\
\text { Sex } \\
\text { BMl at baseline } \\
\text { Smoking }\end{array}$ & $\begin{array}{l}\text { Age } \\
\text { Sex } \\
\text { BMl at baseline } \\
\text { Smoking }\end{array}$ & $\begin{array}{l}\text { Age } \\
\text { Sex } \\
\text { BMl at baseline } \\
\text { Smoking } \\
\text { Education }\end{array}$ & $\begin{array}{l}\text { Age } \\
\text { Sex } \\
\text { BMl at baseline } \\
\text { Smoking } \\
\text { Education } \\
\text { History of gastric ulcers or } \\
\text { bleeding }\end{array}$ \\
\hline
\end{tabular}

*NOS, not otherwise specified; BMI, body mass index.

†This confounder includes three variables; current smoking (yes/no), number of cigarettes/day and number of years of smoking.

$\ddagger$ This confounder refers to the highest level of education (primary school, lower vocational school, high school and higher vocational/university).

cases were identified from the entire cohort, whereas a random sample of the cohort (subcohort) was used for estimation of the accumulated person years in the entire cohort. This subcohort of 5000 men and women was randomly sampled from the entire cohort immediately after baseline measurement and is being followed up biennially for vital status. Subjects in the cohort with prevalent cancer (other than skin cancer) at baseline were excluded, leaving 4774 subcohort members (2336 men and 2438 women).

Incident cancer cases occurring in the entire cohort were identified through annual record linkage to the Netherlands Cancer Registry and the Netherlands Pathology Registry (PALGA). The completeness of cancer follow-up was estimated to be at least $96 \%{ }^{26}$ Further details on the design of the Netherlands Cohort Study on Diet and Cancer and the method of cancer follow-up have been described in previous publications. ${ }^{27} 28$

The present analysis is restricted to the 13.3 years of followup period from September 1986 to December 1999. This is the most recent dataset available for analysis, because cancer registration, linkage to the cancer registry, checks of the reported linkages and the processing of the food frequency questionnaire cause considerable delays.

During this follow-up period, only two subcohort members were lost to follow-up. After the follow-up period of 13.3 years, 142 incident primary adenocarcinomas (M8140-8141, 8190$8231,8260-8263,8310,8430,8480-8490,8560,8570-8572)^{29}$ of the oesophagus (ICD-O-3 C15) and 173 incident, primary adenocarcinomas of the gastric cardia (ICD-O-3 C16.0) were detected. Also, 108 squamous cell carcinomas (M8050-8076) ${ }^{29}$ of the oesophagus (ICD-O-3 C15), 280 adenocarcinomas of the distant stomach (ICD-O-3 C16.1-C16.5) and 208 adenocarcinomas of the stomach with an unspecified localisation
(ICD-O-3 C16.6-C16.9) occurred during this follow-up period (fig 1). All tumours were microscopically confirmed. Among the group of adenocarcinoma of the stomach with an unspecified localisation, 12 tumours $(5.8 \%)$ occurred in the greater curvature of the stomach (ICD-O-3 C16.6), 130 tumours $(62.5 \%)$ had an overlapping sublocalisation within the stomach (ICD-O-3 Cl6.8) and in only 66 tumours $(31.7 \%$ ) the exact location within the stomach (ICD-O-3 C16.9) was unknown.

\section{Baseline questionnaire data}

At baseline, all 120852 cohort members completed a self administered questionnaire on usual dietary intake and other risk factors for cancer, such as anthropometry, smoking habits, physical activity, education and family history of cancer. Questionnaire data of all cases and subcohort members were key entered twice and processed in a manner blinded with respect to case/subcohort status to minimise observer bias in the coding and interpretation of data. BMI at baseline and BMI at age 20 years were calculated using weight at baseline and weight at age 20 years, respectively, divided by height at baseline squared $\left(\mathrm{kg} / \mathrm{m}^{2}\right)$. BMI at baseline was classified into the following categories: $<20.0 \mathrm{~kg} / \mathrm{m}^{2}, 20.0-24.9 \mathrm{~kg} / \mathrm{m}^{2}, 25.0-$ $29.9 \mathrm{~kg} / \mathrm{m}^{2}$ and $\geqslant 30.0 \mathrm{~kg} / \mathrm{m}^{2}$. Subjects with missing values for BMI at baseline were excluded from all analyses (fig 1). For BMI at age 20 years, the categories were $<20.0 \mathrm{~kg} / \mathrm{m}^{2}, 20.0-$ $21.4 \mathrm{~kg} / \mathrm{m}^{2}, 21.5-22.9 \mathrm{~kg} / \mathrm{m}^{2}, 23.0-24.9 \mathrm{~kg} / \mathrm{m}^{2}$ and $\geqslant 25.0 \mathrm{~kg} /$ $\mathrm{m}^{2}$. Change in BMI since age 20 years was calculated as BMI at baseline minus BMI at age 20 years. This variable was categorised as $<0 \mathrm{~kg} / \mathrm{m}^{2}, 0-3.9 \mathrm{~kg} / \mathrm{m}^{2}, 4.0-7.9 \mathrm{~kg} / \mathrm{m}^{2}$ and $\geqslant 8.0 \mathrm{~kg} / \mathrm{m}^{2}$. Subjects with missing values for BMI at age 20 years were excluded from the analyses of BMI at age 20 years and change in BMI (fig 1 ). 


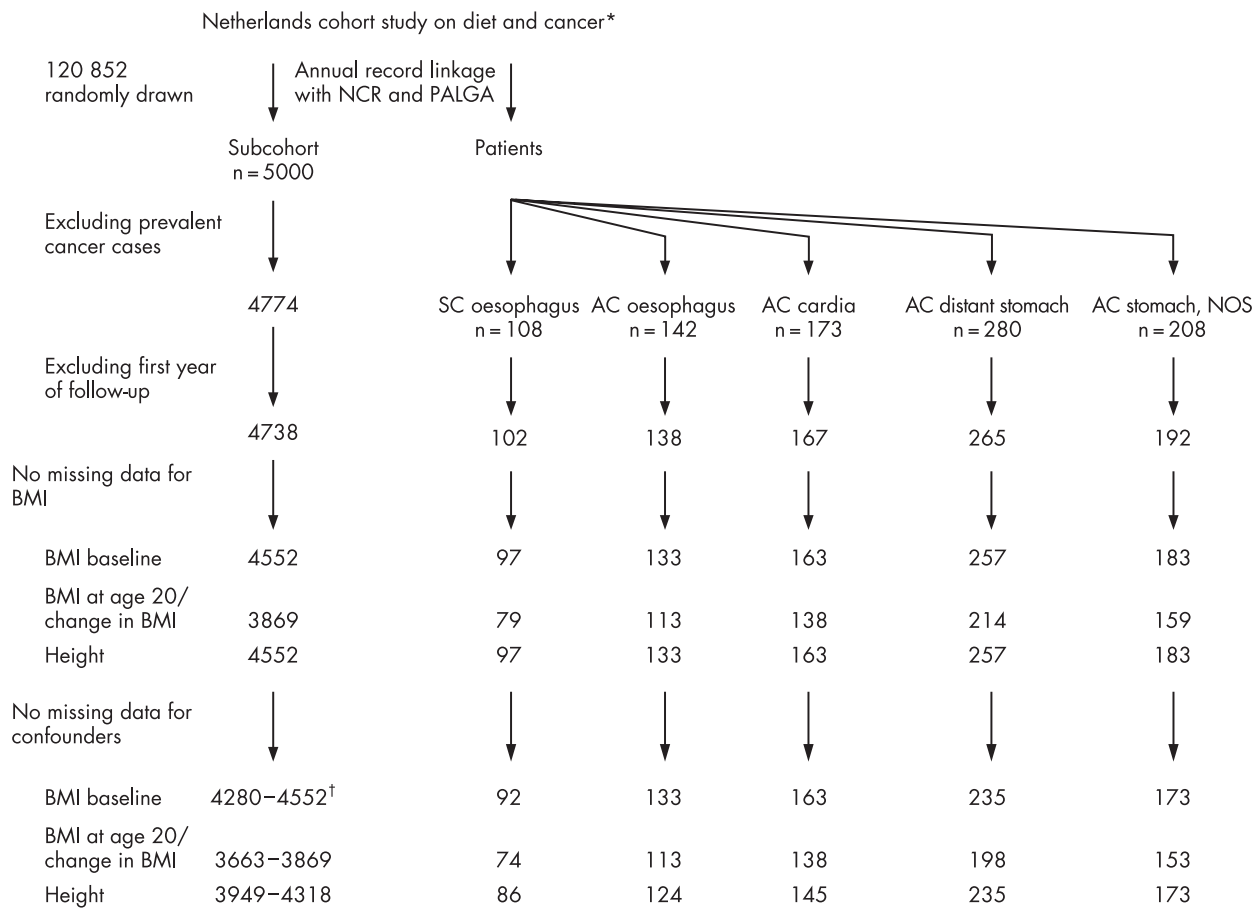

Figure 1 Flow diagram of numbers of subcohort members and cases on whom the analyses were based. *Abbreviations: NCR, Netherlands Cancer Registry; PALGA, Netherlands Pathology Register; SC, squamous cell carcinoma; AC, adenocarcinoma; NOS, not otherwise specified; BMI, body mass index. †Range of subcohort members. Numbers of subcohort members in the analyses were dependent on the different confounder sets for every tumour type in this study.

\section{Statistical analysis}

In the analyses, the first year of follow-up was omitted, because the baseline body weight of cases diagnosed in the first year of follow-up could have been influenced by the presence of preclinical disease (fig 1).

The mean values of the anthropometric variables were compared between cases and subcohort members. Other factors were considered as confounders if they were clearly associated with the anthropometric variables, if they were associated with the cancer risk and if rate ratios changed by more than $10 \%$ after adjustment. The confounders considered were age (continuous), sex, current smoking (yes or no), number of cigarettes per day (continuous), number of years of smoking (continuous), alcohol intake (g/day), vegetable and fruit consumption (g/day), non-occupational physical activity $(<30,30-59,60-89$ and $\geqslant 90$ minutes/day), highest level of education (primary school, lower vocational, high school and higher vocational/university), family history of oesophageal cancer (present or not present in a first degree relative), family history of stomach cancer (present or not present in a first degree relative), medical history of chronic intestinal diseases (yes or no), gastric ulcer or bleeding (yes or no) and reported use of medications (yes or no) such as antacids (ATC code: A02A), ${ }^{30}$ reflux medication (ATC code: A02B), ${ }^{30}$ or lower oesophageal sphincter (LOS) relaxing medication (ATC codes: C01D "nitroglycerins", R03D "aminophyllines", R03A/R03C "beta receptor agonists", A03A/A03C "anticholinergics" and N05B/N05C "benzodiazepines"). ${ }^{30} 31$ In multivariate analyses with anthropometric variables, all rate ratios (RRs) of every tumour type in this study were adjusted for age and sex. The analyses of change in BMI were also further adjusted for BMI at age 20 years, while the analyses of height were further adjusted for BMI at baseline. In addition, a different set of confounders was defined for every tumour type in this study (table 1). Cases and subcohort members with missing data on confounders were excluded from the analyses (fig l).
Incidence RRs and corresponding 95\% confidence intervals (95\% CI) were estimated in Cox proportional hazards models using the Stata statistical software package (Stata Corporation, College Station, TX, USA), after testing of the proportional hazards assumption using the scaled Schoenfeld residuals. ${ }^{32}$ Standard errors were estimated using the robust Hubert-White sandwich estimator to account for additional variance introduced by sampling from the cohort. ${ }^{33}$ To obtain $p$ values for dose-response trends, ordinal exposure variables were fitted as continuous terms in the regression models. Two sided $\mathrm{p}$ values are reported throughout this paper.

\section{RESULTS}

BMI at baseline was higher among cases with adenocarcinoma of the oesophagus and gastric cardia compared to subcohort members, while cases with oesophageal squamous cell carcinoma had a lower BMI at baseline (table 2). At age 20 years, especially, female cases with squamous cell carcinoma and adenocarcinoma of the oesophagus had a higher BMI compared to female subcohort members (mean values, $22.1 \mathrm{~kg} / \mathrm{m}^{2}$ and $22.6 \mathrm{~kg} / \mathrm{m}^{2}$ versus $21.4 \mathrm{~kg} / \mathrm{m}^{2}$, respectively). For men, however, no great differences were observed for BMI at age 20 years between the cases and the subcohort, except for a higher BMI at age 20 years among cases with adenocarcinoma of the gastric cardia.

Table 2 also shows the distribution of the confounding factors among cases and subcohort members. A higher number of current smokers at baseline were found among cases with oesophageal squamous cell carcinoma compared to the other cases and subcohort members. In addition, these cases also consumed more alcohol than the other cases and subcohort members. Especially among women, there were more alcohol consumers among cases with oesophageal squamous cell carcinoma than in the other groups.

The multivariate adjusted RRs for the three BMI variables are shown in table 3 . For both oesophageal and gastric cardia 


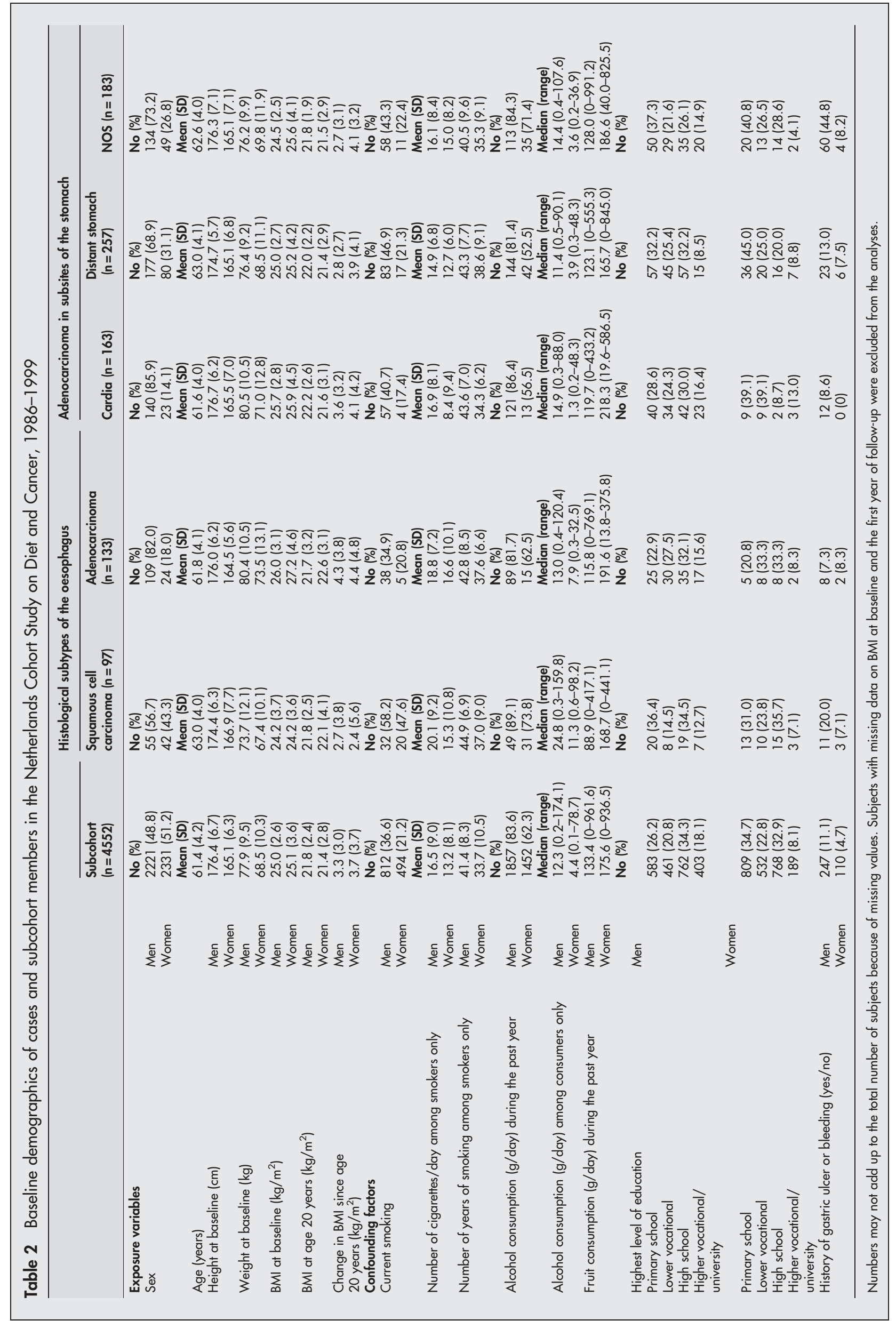


adenocarcinoma, a clearly positive dose-response trend was seen with BMI at baseline ( $p$ for trend 0.001 and 0.002, respectively). However, for oesophageal squamous cell carcinoma a negative trend was found with increasing BMI at baseline ( $\mathrm{p}$ for trend 0.04). No significant associations were found between BMI at baseline and the risk of non-cardia gastric adenocarcinoma. Underweight (BMI $<20.0 \mathrm{~kg} / \mathrm{m}^{2}$ ) was associated with a nearly statistically significant increased risk of squamous cell carcinoma ( $\mathrm{RR}=2.21 ; 95 \% \mathrm{CI} 0.99$ to 4.92 ).

The BMI differences between the cases and the subcohort were more prominent in women than in men, while the cases are mostly men (table 2). However, when the analyses were restricted to men, we still found a strong positive association between BMI at baseline and the risk of oesophageal and gastric cardia adenocarcinoma ( $p$ for trend 0.005 and 0.004, respectively).

BMI at 20 years of age was associated with the risk of adenocarcinoma of the gastric cardia (per $1 \mathrm{~kg} / \mathrm{m}^{2}$ increment, $\mathrm{RR}=1.07 ; 95 \%$ CI 1.00 to 1.15$)$ although the $\mathrm{p}$ for trend in categorical analysis was not significant $(\mathrm{p}=0.17)$. Furthermore, subjects who were overweight (BMI ( $\geqslant 25.0 \mathrm{~kg} /$ $\mathrm{m}^{2}$ ) at 20 years of age had a significantly higher risk of oesophageal squamous cell carcinoma $(\mathrm{RR}=2.49$; 95\% CI 1.15 to 5.40). No significant associations were found between BMI at 20 years of age and the risk of the other tumour types. A gain in BMI of $1 \mathrm{~kg} / \mathrm{m}^{2}$ increment after 20 years of age increased the risk of adenocarcinoma of the oesophagus to $14 \%$. Subjects with a BMI gain of $\geqslant 8.0 \mathrm{~kg} / \mathrm{m}^{2}$ had a 3.4 times higher risk of oesophageal adenocarcinoma compared to subjects with 0 $3.9 \mathrm{~kg} / \mathrm{m}^{2}$ change in BMI (table 3 ). Also for gastric cardia adenocarcinoma a significant positive trend was found with a gain in BMI ( $p$ for trend $=0.02$ ). No associations were found between change in BMI and the other three tumour types. Subjects with weight loss had a significantly higher risk of oesophageal squamous cell carcinoma compared to subjects with a BMI change $0-3.9 \mathrm{~kg} / \mathrm{m}^{2}(\mathrm{RR}=2.57 ; 95 \%$ CI 1.40 to 4.72).

In table 4, the multivariate adjusted RRs for height at baseline are shown. Inverse associations with height were found for oesophageal squamous cell carcinoma and adenocarcinoma of the distant stomach although these associations were not statistically significant $(\mathrm{p}$ for trend $=0.22$ and 0.07 , respectively). A positive, non-statistically significant, trend with increasing height, was found for gastric cardia adenocarcinoma $(\mathrm{p}$ for trend $=0.06)$.

\section{DISCUSSION}

Our results confirm that BMI at baseline is a strong risk factor for adenocarcinoma of the oesophagus and gastric cardia. Also change in BMI during adulthood increased the risks of these tumours, while BMI at 20 years of age was only positively associated with the risk of gastric cardia adenocarcinoma. Furthermore, subjects in the lowest classes of the BMI at baseline $\left(<20.0 \mathrm{~kg} / \mathrm{m}^{2}\right)$ had a higher risk of oesophageal squamous cell carcinoma, although this association was not statistically significant. A significantly higher risk of this tumour was found with weight loss after age 20 years. For height, no statistically significant associations were found with any of the tumour types investigated.

It is unlikely that the results in this prospective cohort study have been affected by selection or information bias. During the 13.3 years of follow-up, only two subcohort members $(0.04 \%)$ were lost to follow-up. It was estimated that coverage of the cancer follow-up of the entire cohort was at least $96 \%{ }^{26}$ Therefore, exposure related loss to follow-up is unlikely.

If the presence of preclinical disease has influenced the weight of the cases, this may lead to a higher risk of cancer with lower BMI (reverse causation), especially when this association would be found for weight loss during adulthood. For this reason, we excluded cases diagnosed in the first year of followup. However, it is not clear whether this is sufficient.

In additional analyses in which we excluded none, one, two and five follow-up years, we found no differences in the strength of the association between BMI at baseline and either of the five tumour types investigated. So, the strong positive association between BMI at baseline and the risk of oesophageal and gastric adenocarcinoma was not dependent on the number of follow-up years excluded.

Since the data on the anthropometry in this study are self reported, misclassification of exposure is a potential source of bias. Some studies have found that self reported and measured weight and height were strongly correlated. ${ }^{34}{ }^{35}$ Other studies also found that men are more inclined to over-report their height, while women are more inclined to under-report their weight. $^{3436}$ These misclassifications, however, lead to lower estimates of the BMI and probably to an underestimate of the effect of BMI on the risk of the tumour types in this study.

BMI at 20 years of age was calculated using the self reported weight at age 20 years. Because it is difficult to remember the weight at age 20 years, some recall bias may have occurred for this variable. However, this recall bias is expected to be nondifferential.

Another potential source of bias is misclassification of tumours. It is unlikely, however, that this misclassification has attenuated our results. Firstly, there is a clear difference in the relative risks of squamous cell carcinoma and adenocarcinoma of the oesophagus and of adenocarcinoma of gastric cardia and other parts of the stomach. Secondly, the association with BMI is very strong for both oesophageal and gastric cardia adenocarcinoma. In addition, the associations of these tumours with BMI are very similar. So, misclassification of these tumours had to be very large to lead to these results. Therefore, it is unlikely that the associations found in this study are attenuated by tumour misclassification.

A recently published meta-analysis found a dose dependent association between a higher BMI and the risk of adenocarcinoma of the oesophagus and possibly of the gastric cardia. ${ }^{8}$ Of the three prospective studies in this meta-analysis, two studies also found higher risks of adenocarcinoma of the oesophagus and/or gastric cardia with BMI, ${ }^{13}{ }^{17}$ while the third study found no association between BMI and gastric cardia adenocarcinoma. ${ }^{18}$ However, the study of Tran et al ${ }^{18}$ was based on a Chinese population who on average is leaner than Western populations and, therefore, has a different distribution of the BMI. Furthermore, two of the studies in this meta-analysis found an inverse trend between an increasing BMI and the risk of oesophageal squamous cell carcinoma, ${ }^{13}{ }^{18}$ as was also found in our study.

Only three case-control studies have investigated the effects of BMI at 20 years of age. ${ }^{1415}$ All three found significant higher risks for oesophageal and/or gastric cardia adenocarcinoma with increasing BMI at 20 years of age. Lagergren et al ${ }^{9}$ also found a statistically significant higher risk of oesophageal squamous cell carcinoma, while Wu et al ${ }^{14}$ found a significant positive trend with increasing BMI at 20 years of age for adenocarcinoma of the distant stomach. In our study, however, no significant risk estimates were found with BMI at 20 years of age, except for gastric cardia adenocarcinoma. Furthermore, we found that the associations for BMI at 20 years of age were less obvious compared to BMI at baseline. $\mathrm{Wu}$ et al also found a stronger association between the current BMI and oesophageal adenocarcinoma, while for gastric cardia adenocarcinoma, the association with BMI at 20 years of age was stronger. ${ }^{14}$ 


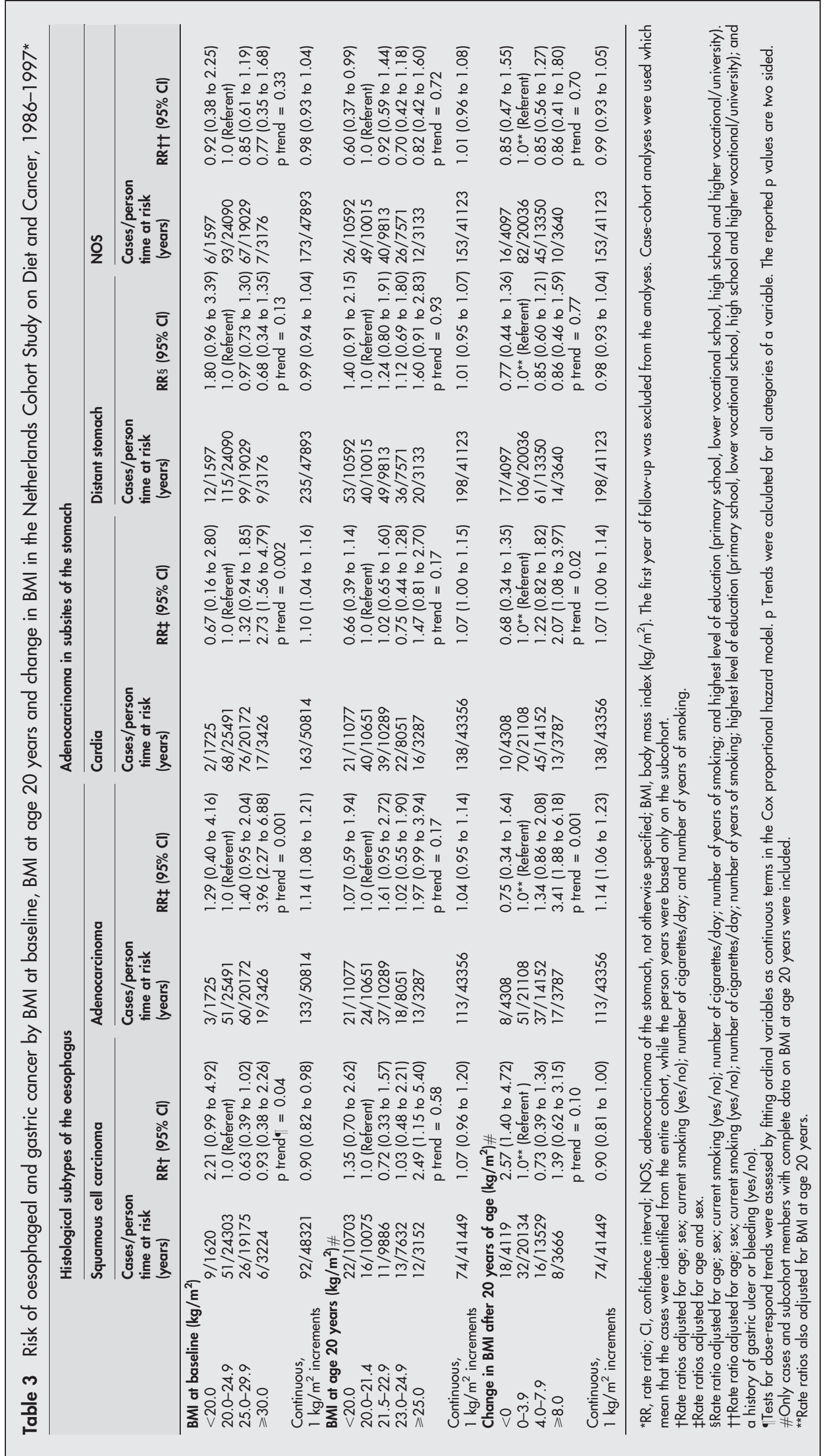




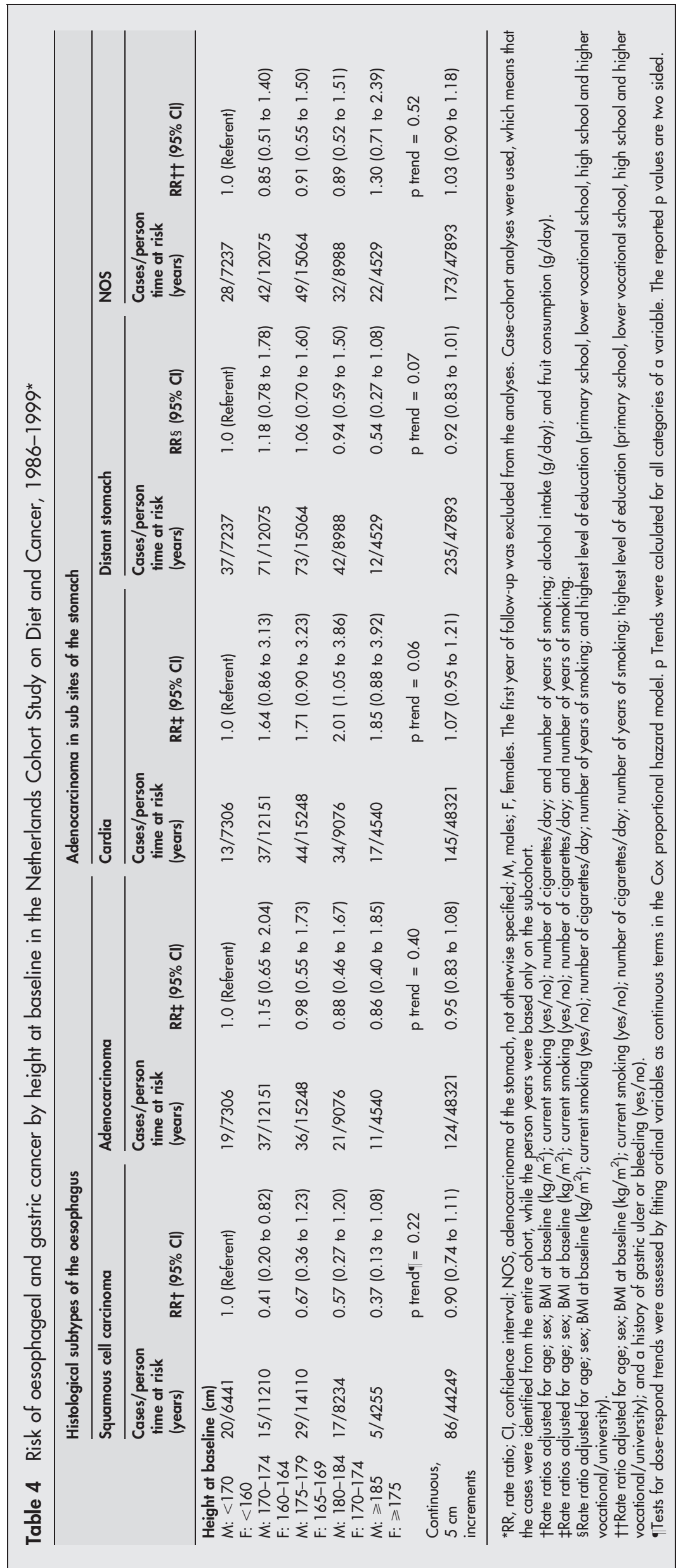

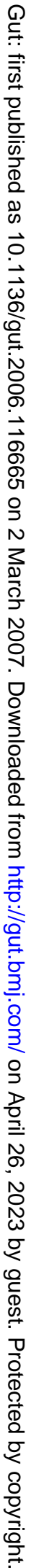


In our study, higher risks of oesophageal and gastric cardia adenocarcinoma were found with gain in BMI during adulthood compared to $0-3.9 \mathrm{~kg} / \mathrm{m}^{2}$ change in BMI. Chow et al also found a significantly higher risk of oesophageal adenocarcinoma for subjects with a weight change $\geqslant 20.87 \mathrm{~kg}$ compared to subjects with $0-2.27 \mathrm{~kg}$ change in weight $(\mathrm{OR}=2.1 ; 95 \% \mathrm{CI}$ 1.2 to 3.8 ), while they found no association with gastric cardia adenocarcinoma. $^{5}$

A possible explanation for this strong association between BMI and risk of adenocarcinoma of the oesophagus and gastric cardia is the effect of high BMI on gastro-oesophageal reflux. A higher BMI is thought to increase the intra-abdominal pressure that can lead to a higher frequency of this reflux..$^{20-24}$ Chronic reflux may damage the oesophageal squamous cell epithelium that can change in a metaplastic epithelium, a condition called Barrett's oesophagus. This condition is thought to be a premalignant lesion for adenocarcinoma of the oesophagus.

Furthermore, we found that change in BMI during adulthood was positively related to adenocarcinoma of the oesophagus, while no association was found with BMI at age 20 years. It is unknown as yet whether a high BMI itself or especially an increase in BMI during adulthood will lead to a higher frequency of gastro-oesophageal reflux. One study found that even a moderate gain in weight among people of normal weight may cause or exacerbate symptoms of reflux which may increase the risk of this tumour. ${ }^{37}$ Further research is needed on the association between change in weight during adulthood and the frequency and severity of gastro-oesophageal reflux.

It is yet unclear what the exact role of this mechanism is for adenocarcinoma of the gastric cardia, although a modest but significant association with gastro-oesophageal reflux symptoms and the risk of this tumour was found in one study. ${ }^{24}$

In this study, it was not possible to evaluate this mechanism by reflux on the risk of oesophageal and gastric cardia adenocarcinoma, because we did not have information on the frequency or severity of reflux symptoms of the participants. This information possibly could be obtained from the data on the use of reflux medications. However, because the use of these medications is self reported and participants were asked to report only medications that were used for more than six months, it is likely that this information is incomplete. In additional analyses, in which the use of antacids, reflux and LOS relaxing medication were added as extra confounders, we found no changes in the association between BMI at baseline and the risk of oesophageal and gastric cardia adenocarcinoma, which can be explained by the low reported prevalence of the use of these medications in our study population.

In this study, no association was found between height and adenocarcinoma of the oesophagus, which was also found in the Norwegian cohort study. ${ }^{17}$ In contrast, one case-control study found height to be a risk factor for this tumour, ${ }^{14}$ while two others found a lower risk of oesophageal adenocarcinoma with increasing height. ${ }^{5}$ Furthermore, the Norwegian study found a protective effect of height on oesophageal squamous cell carcinoma. ${ }^{17}$ This trend was also seen in our study, although it was not significant. The Chinese cohort study, however, found height to be a risk factor for this tumour. ${ }^{18}$ But a Chinese population is on average shorter than Western populations, which may explain these differences in results.

This study confirms a strong dose dependent association between BMI and the risk of adenocarcinoma of the oesophagus and gastric cardia. No associations were found with BMI at age 20 years, while change in BMI during adulthood was found to be a strong risk factor, especially for oesophageal adenocarcinoma. In this relatively lean population, $30.2 \%$ of oesophageal adenocarcinoma and $21.8 \%$ of gastric cardia adenocarcinoma could be attributed to overweight or obesity.
Since the conception of the cohort, obesity has become more prevalent in most Western societies, including the Netherlands and it is likely that the increasing prevalence of overweight and obesity has contributed to the rising incidence of adenocarcinoma of the oesophagus and gastric cardia.

\section{ACKNOWLEDGEMENTS}

We are indebted to the participants of this study and further wish to thank the cancer registries (IKA, IKL, IKMN, IKN, IKO, IKR, IKST, IKW, IKZ and VIKC) and the Netherlands Nationwide Registry of Pathology (PALGA). We also thank Dr A Volovics and Dr A Kester for statistical advice; $S$ van de Crommert, H Brants, J Nelissen, C de Zwart, M Moll, W van Dijk, M Jansen and A Pisters for assistance; and $\mathrm{H}$ van Montfort, L van den Bosch and J Berben for programming assistance.

\section{Authors' affiliations \\ Audrey H H Merry, Leo J Schouten, Department of Epidemiology, \\ NUTRIM, Maastricht University, Maastricht, Netherlands \\ R Alexandra Goldbohm, Department of Food and Chemical Risk Analysis, TNO Quality of Life, Zeist, Netherlands \\ Piet A van den Brandt, Department of Epidemiology, NUTRIM, Maastricht University, Maastricht, Netherlands}

Grant support: This study was financially supported by the Dutch Cancer Society (UM 2006-3562).

Competing interests: None.

\section{REFERENCES}

1 Botterweck AA, Schouten $\sqcup$, Volovics A, et al. Trends in incidence of adenocarcinoma of the oesophagus and gastric cardia in ten European countries. Int J Epidemiol 2000;29:645-54.

2 Wijnhoven BP, Louwman MW, Tilanus HW, et al. Increased incidence of adenocarcinomas at the gastro-oesophageal junction in Dutch males since the 1990s. Eur J Gastroenterol Hepatol 2002;14:115-22.

3 Blot WJ, Devesa SS, Kneller RW, et al. Rising incidence of adenocarcinoma of the esophagus and gastric cardia. JAMA 1991;265:1287-9.

4 Pohl H, Welch HG. The role of overdiagnosis and reclassification in the marked increase of esophageal adenocarcinoma incidence. J Natl Cancer Inst 2005;97:142-6.

5 Chow WH, Blot WJ, Vaughan TL, et al. Body mass index and risk of adenocarcinomas of the esophagus and gastric cardia. J Natl Cancer Inst 1998;90:150-5.

6 Visscher TL, Kromhout D, Seidell JC. Long-term and recent time trends in the prevalence of obesity among Dutch men and women. Int J Obes Relat Metab Disord 2002;26:1218-24.

7 Calle EE, Thun MJ. Obesity and cancer. Oncogene 2004;23:6365-78.

8 Kubo A, Corley DA. Body mass index and adenocarcinomas of the esophagus or gastric cardia: a systematic review and meta-analysis. Cancer Epidemiol Biomarkers Prev 2006;15:872-8.

9 Lagergren J, Bergstrom R, Nyren O. Association between body mass and adenocarcinoma of the esophagus and gastric cardia. Ann Intern Med 1999;130:883-90.

10 Kabat GC, Ng SK, Wynder EL. Tobacco, alcohol intake, and diet in relation to adenocarcinoma of the esophagus and gastric cardia. Cancer Causes Control 1993;4:123-32.

11 Vaughan TL, Davis S, Kristal A, et al. Obesity, alcohol, and tobacco as risk factors for cancers of the esophagus and gastric cardia: adenocarcinoma versus squamous cell carcinoma. Cancer Epidemiol Biomarkers Prev 1995;4:85-92.

12 Gallus S, La Vecchia C, Levi F, et al. Leanness and squamous cell oesophageal cancer. Ann Oncol 2001;12:975-9.

13 Lindblad M, Rodriguez LA, Lagergren J. Body mass, tobacco and alcohol and risk of esophageal, gastric cardia, and gastric non-cardia adenocarcinoma among men and women in a nested case-control study. Cancer Causes Control 2005; 16:285-94.

14 Wu AH, Wan P, Bernstein L. A multiethnic population-based study of smoking, alcohol and body size and risk of adenocarcinomas of the stomach and esophagus (United States). Cancer Causes Control 2001;12:721-32.

15 Cheng KK, Sharp L, McKinney PA, et al. A case-control study of oesophageal adenocarcinoma in women: a preventable disease. Br J Cancer 2000;83:127-32

16 Tretli S, Robsahm TE. Height, weight and cancer of the oesophagus and stomach a follow-up study in Norway. Eur J Cancer Prev 1999;8:115-22.

17 Engeland A, Tretli S, Bjorge T. Height and body mass index in relation to esophageal cancer; 23-year follow-up of two million Norwegian men and women. Cancer Causes Control 2004;15:837-43.

18 Tran GD, Sun XD, Abnet CC, Fan JH, et al. Prospective study of risk factors for esophageal and gastric cancers in the Linxian general population trial cohort in China. Int J Cancer 2005;1 13:456-63. 
19 Ji BT, Chow WH, Yang G, et al. Body mass index and the risk of cancers of the gastric cardia and distal stomach in Shanghai, China. Cancer Epidemiol Biomarkers Prev 1997:6:481-5.

20 La Vecchia C, Negri E, Lagiou P, et al. Oesophageal adenocarcinoma: a paradigm of mechanical carcinogenesis? Int J Cancer 2002;102:269-70.

21 Kim R, Weissfeld JL, Reynolds JC, et al. Etiology of Barrett's metaplasia and esophageal adenocarcinoma. Cancer Epidemiol Biomarkers Prev 1997;6:369-77.

22 Murray L, Johnston B, Lane A, et al. Relationship between body mass and gastrooesophageal reflux symptoms: the Bristol Helicobacter Project. Int J Epidemiol 2003;32:645-50.

23 Nilsson $M$, Johnsen $R, Y e W$, et al. Obesity and estrogen as risk factors for gastroesophageal reflux symptoms. JAMA 2003;290:66-72.

24 Wu AH, Tseng CC, Bernstein L. Hiatal hernia, reflux symptoms, body size, and risk of esophageal and gastric adenocarcinoma. Cancer 2003;98:940-8.

25 Freeman HJ. Risk of gastrointestinal malignancies and mechanisms of cancer development with obesity and its treatment. Best Pract Res Clin Gastroenterol 2004; 18:1 167-75.

26 Goldbohm R, Van Den Brandt PA, Dorant E. Estimation of the coverage of Dutch municipalities by cancer registries and PALGA based on hospital discharge data. Tijdschr Soc Gezondheidsz 1994;72:80-4

27 Van den Brandt PA, Goldbohm RA, Van 't Veer P, et al. A large-scale prospective cohort study on diet and cancer in the Netherlands. J Clin Epidemiol 1990:43:285-95.
28 Van den Brandt PA, Schouten U, Goldbohm RA, et al. Development of a record linkage protocol for use in the Dutch Cancer Registry for Epidemiological Research. Int J Epidemiol 1990;19:553-8.

29 Parkin DM, Shanmugaratnam K, Sobin L, et al. Histological groups for comparative studies. Technical report. Lyon: International Agency for Research on Cancer (IARC), 1998, Report No, 31.

30 WHO Collaborating Centre for Drug Statistics Methodology. http:// www.whocc.no/atcddd/welcome.html (accessed 21 Feb 2005).

31 Lagergren J, Bergstrom R, Adami $\mathrm{HO}$, et al. Association between medications that relax the lower esophageal sphincter and risk for esophageal adenocarcinoma. Ann Intern Med 2000;133:165-75

32 Schoenfeld D. Partial residuals for the proportional hazards regression model. Biometrika 1982;69:239-41.

33 Lin DY, Wei U. The robust interference for the Cox proportional hazards model. J Am Stat Assoc 1989;84:1074-8.

34 Nieto-Garcia FJ, Bush TL, Keyl PM. Body mass definitions of obesity: sensitivity and specificity using self-reported weight and height. Epidemiology 1990;1:146-52.

35 Stunkard AJ, Albaum JM. The accuracy of self-reported weights. Am J Clin Nutr 1981;34:1593-9.

36 Palta M, Prineas RJ, Berman R, et al. Comparison of self-reported and measured height and weight. Am J Epidemiol 1982;115:223-30.

37 Jacobson BC, Somers SC, Fuchs CS, et al. Body-mass index and symptoms of gastroesophageal reflux in women. N Engl J Med 2006;354:2340-8.

\section{EDITOR'S QUIZ: GI SNAPSHOT}

\section{Haemorrhagic gastritis in a neurologically impaired boy}

\section{Clinical presentation}

A 7-year-old boy, affected by spastic quadriplegia secondary to perinatal respiratory distress, presented with a 15-day history of severe abdominal pain. Paracetamol and omeprazole brought no relief. On physical examination, the boy was in a poor general state, but with normal vital signs, and with a flat and soft abdomen without tenderness. There was no organomegaly. However, diffuse hyperkeratosis, joint pain and petechial haemorrhages on the legs, together with swollen and friable gums were present. He had no history of trauma, fever or weight loss. Initial blood tests for haemachrome, electrolytes, coagulation factors, liver and muscle enzymes, renal function, rheumatoid factors and infectious agents were all normal. The erythrocyte sedimentation rate was $40 \mathrm{~mm} / \mathrm{h}$ and C-reactive protein was $5.87 \mathrm{mg} / \mathrm{dl}$ (reference range $<0.50$ ). Cardiac function and abdominal ultrasound evaluation were unremarkable. Upper endoscopy showed a haemorrhagic aspect of the antrum with diffuse petechiae, very similar to that observed at the cutaneous level (fig 1) without any evidence of Helicobacter pylori infection.

\section{Question}

What is the diagnosis?

See page 1535 for answer

R Berni Canani, A G Fratellanza, E Del Giudice Department of Paediatrics, University "Federico II" of Naples, Naples, Italy

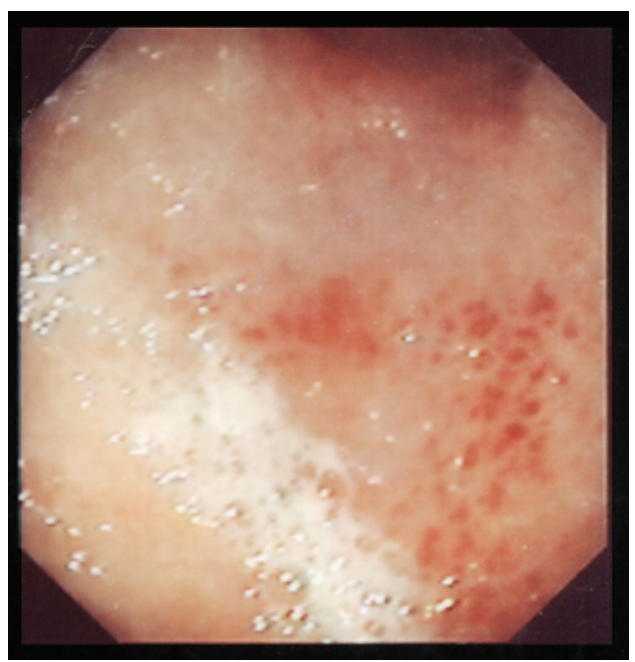

Figure 1 Endoscopic view of the antrum.

Correspondence to: Professor Roberto Berni Canani, Department of Paediatrics, University "Federico II" of Naples, Via S. Pansini, 580131 Naples, Italy; berni@unina.it

doi: $10.1136 /$ gut.2006.106567 